\title{
A Longitudinal Examination of 10-year Change in Vocational and Educational Activities for Adults with Autism Spectrum Disorders
}

\author{
Julie Lounds Taylor, \\ Department of Pediatrics, Vanderbilt University School of Medicine and the Monroe Carell Jr. \\ Children's Hospital at Vanderbilt \\ Vanderbilt Kennedy Center, and \\ Department of Pediatrics, Vanderbilt University School of Medicine and the Monroe Carell Jr. \\ Children's Hospital at Vanderbilt \\ Marsha R. Mailick \\ Waisman Center, University of Wisconsin-Madison
}

\begin{abstract}
The transition from adolescence to adulthood has been shown to be a time of amplified risk for individuals with autism spectrum disorders (ASD). It is unknown, however, whether problems in educational attainment and employment in the years after high school exit represent "momentary perturbations" in development or a "turning point" with long-lasting effects throughout adulthood. The present study addressed this question by examining 10-year trajectories of vocational and educational activities for adults with ASD, as well as the personal characteristics and environmental resources that predicted these activities. Participants were 161 adults with ASD (ages 18-52 at the start of the study, M=30.9 years) who were part of a larger longitudinal study. Data were collected at 6 time points over a 10-year period. Results indicated significant declines in the level of independence and engagement in vocational/educational activities over the study period, particularly for women. Greater independence in vocational activities was found for those with more independence in activities of daily living. Net of personal characteristics, receipt of more services was marginally related to greater improvement in vocational independence.
\end{abstract}

\section{Keywords}

autism spectrum disorder; adult; vocational activities; employment; sex differences

Because of its pervasive contextual and social role changes, the transition from adolescence to adulthood is one of the most critical of all transitions in the life course (Schulenberg, Sameroff, \& Cicchetti, 2004). As youth navigate this stage of life, they encounter increasing less normatively, institutionally, and culturally-imposed structure; this lack of structure can be liberating for some youth, but debilitating for others (Schulenberg, et al., 2004). For those who struggle during this time, a key developmental question is whether their difficulties reflect a "momentary perturbation" or a "turning point" that changes the trajectory of their adult development (Schulenberg, et al., 2004).

Correspondence concerning this article should be addressed to Julie Lounds Taylor, Vanderbilt Kennedy Center, Peabody Box 40 230 Appleton Place; Nashville, TN 37203. Julie.l.taylor@vanderbilt.edu. Phone: (615) 343-5659.. 
Youth with autism spectrum disorders (ASD) appear to be particularly affected by the loss of structure when transitioning from adolescence into adulthood. At high school exit, they lose the entitlement to many (and sometimes all) of the federally-mandated services that they received while in school. In most cases, youth with ASD enter a world of adult services that is underfunded and plagued by long waiting lists, with a dearth of appropriate opportunities to achieve a maximum level of adult independence (Howlin, Alcock, \& Burkin, 2005). Perhaps due, at least in part, to the loss of structure and support, the improvements in autism symptoms, problem behaviors, and the quality of the mother-child relationship that have been shown to occur while youth with ASD are in high school tend to slow down or even stop after high school exit (Taylor \& Seltzer, 2010, 2011a). Relative to youth with other disabilities, youth with ASD are more likely to receive no formal services after exiting high school (Shattuck, Wagner, Narendorf, Sterzing, \& Hensley, 2011), and one-half of these youth have no vocational or educational activities in the years immediately following high school exit (Shattuck et al., 2012).

However, researchers have yet to examine whether problematic outcomes observed in the years immediately after high school exit persist, worsen, or improve throughout adulthood. It may be that low rates of employment and engagement, for example, represent momentary perturbations in development (Schulenberg, et al., 2004), as individuals with ASD and their families struggle to master the adult service system and identify appropriate educational and vocational activities. Alternatively, the loss of structure and support at high school exit might represent a turning point that signifies a long-lasting change in the course of adult development. The present study explored this question by examining trajectories of vocational and educational activities over a 10-year period for adults with ASD. If we find that vocational/educational activities improve over time, then evidence would be provided indicating that difficulties following high school exit are a momentary perturbation. However, if these activities stall or decline over time, then our analyses would provide evidence that the difficulties following high school exit are a more fundamental turning point in development. We also examined the personal characteristics and contextual resources measured at the start of the study that were associated with concurrent vocational and educational activities as well as change in these activities over the study period. Given the prevalence of ASD (1 in 88 children; Centers for Disease Control and Prevention, 2012), investigation of how adulthood is negotiated by such individuals is highly significant.

\section{Predictors of Vocational and Educational Activities}

Although it is generally accepted that development is a function of both personal and contextual factors (Sameroff, 2000), most research predicting outcomes for adults with ASD has focused only on personal characteristics. This study examined both personal characteristics and contextual resources as predictors of vocational/educational activities among adults with ASD.

\section{Personal characteristics}

The most consistent correlate of adult outcomes in past research is intellectual disability (ID); individuals who have ASD without ID have more independent work and residential arrangements compared to those with ASD and ID (Eaves \& Ho, 2008; Farley et al., 2009; Howlin, Goode, Hutton, \& Rutter, 2004). However, there is some evidence to suggest that their trajectories may not be as favorable. Specifically, we found that in the years after leaving high school, those with ASD without ID experienced a much more pronounced slowing of improvement in their symptoms and behaviors over time compared to those with ASD and ID (Taylor \& Seltzer, 2010). 
Indices of behavioral functioning such as autism symptoms, maladaptive behaviors, and functional independence are also related to vocational/educational activities in adulthood. Adults with ASD who have fewer autism symptoms (Eaves \& Ho, 2008; Howlin, et al., 2004) and maladaptive behaviors (Taylor \& Seltzer, 2011b) tend to have better vocational outcomes. Autism symptoms, such as insistence on sameness, difficulty with change in routine, or restricted interests, as well as maladaptive behaviors such as aggression or uncooperative behavior, interfere with day-to-day functioning, and thus limit the possible vocational and educational activities available to the adult with ASD. Alternatively, higher levels of functional independence in activities of daily living are related to greater independence in vocational activities for individuals with ASD (Farley, et al., 2009; Taylor \& Seltzer, 2011b).

We also examined whether the sex of the adult with ASD was related to vocational and educational activities and change in activities over time. Although the inclusion of sex as a possible explanatory factor is nearly ubiquitous in studies of employment in the general population, there is little research that has considered how sex might influence outcomes for adults with ASD. ASD affects 4.5 times as many males as females (Centers for Disease Control and Prevention, 2012), and as a result most of our information about ASD has come from samples of males, or from samples where there are too few females to separately analyze by sex. Thus, the degree of poor adult outcomes among women with ASD is not well understood. There is some research to suggest, however, that gender stereotypes affect individuals with disabilities, resulting in lowered achievement expectations for women with disabilities relative to men (Powers, Hogansen, Geenen, Powers, \& Gil-Kashiwabara, 2008).

\section{Contextual resources}

The effects of context-level factors on the vocational and educational activities of individuals with ASD are far less studied than person-level factors. Family income might play an important role in the vocational and educational opportunities available to adults with ASD. Shattuck and colleagues $(2011,2012)$ found that, relative to young adults with ASD whose families had higher incomes, those whose families had lower incomes were less likely to receive any formal services and more likely to have no educational or vocational activities in the years after high school exit. Taylor and Seltzer (2010) found that individuals with ASD whose families had lower incomes were more negatively impacted by the transition out of high school relative to those with higher incomes, perhaps because of limited access to appropriate daytime activities. Thus, for the present study, we expected that higher family income would increase the vocational and educational options available to adults with ASD, leading to more positive outcomes.

Although studies have yet to examine the role of formal services in vocational and educational activities of individuals with ASD, research in other populations suggests that service availability and receipt might also be an important contextual resource. For example, Taylor and Hodapp (2012) found that adults with disabilities who had no vocational/ educational activities tended to receive fewer formal services, and also had a greater number of unmet service needs. Similarly, Esbensen, Bishop, Seltzer, Greenberg, and Taylor (2010) found that receipt of a greater number of services was related to more independent outcomes for adults with Down syndrome. In another study, we found that having fewer unmet service needs was related to an attenuation of the negative impact of leaving high school on the mother-child relationship for youth with ASD (Taylor \& Seltzer, 2011a). Because the receipt of formal services (such as transportation or job placement services) likely increases opportunities for adults with ASD, we expected that service receipt would impact their vocational and educational activities. 
Finally, we hypothesized that the size of parental social support networks would be related to vocational and educational activities of adults with ASD. Although previous research has not examined the role of parental social support in outcomes of these adults, one of the key functions of social relationships is information acquisition (Carstensen, 1992). Parents of individuals with ASD who have larger support networks will potentially have more people to draw upon when gathering information about services and employment opportunities for their son or daughter, and therefore we expected that their sons and daughters would have better outcomes relative to adults with ASD whose parents were more socially isolated.

\section{The Present Study}

The present study examined 10-year trajectories of vocational and educational activities in adults with ASD who averaged 30 years of age at the beginning of the study (range $=18-52$ years). Although difficulties in vocational activities are well-documented among adults with ASD (Eaves \& Ho, 2008; Howlin, et al., 2004; Taylor \& Seltzer, 2012), most studies measure outcomes at a single point in time. Longitudinal analyses are needed to reveal the dynamics of vocational/educational activities throughout adulthood and to determine whether risk for low achievement persists or abates over time.

We had three specific aims. First, we examined whether the adults became more independent, stayed the same, or became less independent in their vocational and educational activities over a 10-year period. To do this we estimated the slope of Vocational Index scores (Taylor \& Seltzer, 2012). We hypothesized that Vocational Index scores would increase over time, on average, signifying increasing independence, due to improvements in the autism behavioral phenotype over adulthood (Shattuck et al., 2007; Taylor \& Seltzer, 2010), as well as increasing family expertise over time in navigating the adult disability service system.

Second, we tested which personal characteristics (ID status, maladaptive behaviors, autism symptoms, independence in activities of daily living, and sex) and contextual resources (family income, formal services received and needed, and parental social support), measured at the start of the study, independently predicted concurrent Vocational Index scores. We hypothesized that fewer problem behaviors and autism symptoms, greater independence in activities of daily living, and male sex, as well as greater contextual resources (higher income, more services received, fewer unmet service needs, and greater parental support) would be associated with higher concurrent Vocational Index scores.

Our third aim was to examine which personal characteristics and contextual resources predicted change in Vocational Index scores over time. We had two hypotheses associated with this aim: 1) Consistent with our earlier work (Taylor \& Seltzer, 2010, 2011a), we expected that adults without ID would have higher Vocational Index scores at the start of the study, but that their scores would increase less over time relative to those with ID, resulting in a smaller difference between the groups by the end of the study period; and 2) greater contextual resources would increase opportunities for the adult with ASD over time, as adults with more formal and informal supports might be able to increasingly pursue and maintain more independent vocational placements.

\section{Method}

\section{Sample and Procedure}

The present analysis used a subsample $(n=161)$ drawn from our larger longitudinal study of families of adolescents and adults with ASD $(N=406$; Seltzer et al., 2011). The criteria for inclusion in the larger study were that the son or daughter with ASD was age 10 or older 
(age range $=10$ to 52 at the beginning of the study), had received an ASD diagnosis (autistic disorder, Asperger disorder, or pervasive developmental disorder- not otherwise specified) from an educational or health professional, and had a researcher-administered Autism Diagnostic Interview-Revised (ADI-R; Lord, Rutter, \& Le Couteur, 1994) profile consistent with the diagnosis. Nearly all of the sample members (94.6\%) met the ADI-R lifetime criteria for a diagnosis of autistic disorder. Case-by-case review of the other sample members $(5.4 \%)$ determined that their ADI-R profile was consistent with their ASD diagnosis (i.e., meeting the cutoffs for reciprocal social interaction and repetitive behaviors for Asperger's disorder, and for reciprocal social interaction and either impaired communication or repetitive behaviors for Pervasive Developmental Disorder - Not Otherwise Specified). Half of the participants lived in Wisconsin $(n=202)$ and half in Massachusetts $(n=204)$. We used identical recruitment and data-collection methods at both sites. Families received information about the study through service agencies, schools, and clinics; those who were interested contacted a study coordinator and were subsequently enrolled. Six waves of data have thus far been collected and are available for analysis: four waves collected every 18 months from 1998 to 2003, spanning a 4.5-year period; a fifth wave collected in 2008; and a sixth wave collected in 2010. The amount of time between the first and sixth time point for each person ranged from 9.1 to 11.4 years $(M=10.34, S D=$. 45). At each time point, data were collected from the primary caregiver, who was usually the mother, via in-home interviews that typically lasted 2 to 3 hours and via self-administered questionnaires.

The present analyses make use of all six waves of data (referred to as Time 1 through Time 6). We included all families whose son or daughter with ASD had exited high school before Time 1, and who had at least one subsequent time point of vocational or educational data. By focusing on this sample, it was possible to examine 10-year change in the vocational and educational activities of adults with ASD. Of a possible 164 sample members who met the above inclusion criteria, there were three who were dropped due to missing data on key variables. This resulted in a final sample of 161 parent-adult child dyads.

The adults with ASD included in this analysis averaged 30.9 years of age $(S D=8.3)$ at the first time point of the study, with a range from 18.4 to 52.1 years. Approximately threefourths $(72.0 \%)$ were male, $80.7 \%$ had comorbid ID, and $69.6 \%$ were verbal, as indicated by daily functional use of at least three-word phrases. About $40 \%$ (40.4\%) of the adults were living with the responding parent or another relative at Time 1, with $42.2 \%$ living in a community residence, $10.6 \%$ living in a semi-independent living arrangement, $3.7 \%$ living in a public or private institution or a foster home, and $3.1 \%$ living independently.

The parent sample was composed of 155 mothers and 6 fathers at Time 1. At Time 1, the participating parent in this subsample ranged from 41.4 years to 81.9 years of age $(M=59.9$, $S D=9.8)$. Approximately one-half $(47.8 \%)$ had attained at least a bachelor's degree. Twothirds of parents were married at Time $1(67.9 \%)$ and $95.7 \%$ were Caucasian. The median family household income for parents of adults in this sample was between $\$ 40,000$ and $\$ 45,000$ in 1998 (at Time 1), which is slightly lower than the median income for all family households in the United States in 1998 (\$47,469); (U.S. Census Bureau, 1999). Further descriptive information about this sample and attrition analyses are presented in the supplemental material.

\section{Measures}

Outcome Variable: Vocational and Educational Activities-The Vocational Index (Taylor \& Seltzer, 2012) was used to classify the vocational and educational activities of the adults with ASD at each time point of the study. A full description of the development of the Vocational Index, including detailed coding decision rules, complete category descriptions, 
and distribution of scores for the larger sample can be found in Taylor and Seltzer (2012). This classification scheme is composed of nine ordered, mutually-exclusive categories; ordering of categories reflects the independence necessary to achieve a vocational/ educational activity, as well as whether the adult participated in activities for more than 10 hours a week. Vocational Index scores are as follows: $1=$ no vocational/educational activities; 2 = volunteering or non-degree seeking education only; 3 = sheltered vocational setting (e.g., sheltered workshop or adult day center) for 10 hours a week or less; $4=$ sheltered vocational setting greater than 10 hours a week; $5=$ sheltered vocational setting and employment in the community; 6 = supported employment in the community for 10 hours a week or less; $7=$ supported employment in the community for greater than 10 hours a week; 8 = degree-seeking educational program or employment in the community without supports for a total of 10 hours a week or less; $9=$ degree-seeking educational program or employment in the community without supports greater than 10 hours a week. Inter-rater reliability was excellent at 94\% (Cronbach's alpha $=.92$; Taylor \& Seltzer, 2012).

\section{Time-varying, Within-Persons Independent Variables}

Maladaptive behaviors-Parents completed the Behavior Problems subscale of the Scales of Independent Behaviors - Revised (SIB-R; Bruininks, Woodcock, Weatherman, \& Hill, 1996) at each of the six times of measurement. This subscale measures maladaptive behaviors, grouped in three domains (Bruininks, et al., 1996): internalized behaviors (hurtful to self, unusual or repetitive habits, withdrawal or inattentive behavior), externalized behaviors (hurtful to others, destructive to property, disruptive behavior), and asocial behaviors (socially offensive behavior, uncooperative behavior). Parents who indicated that their son or daughter displayed a given behavior problem during the past six months then rated the frequency $(1=$ less than once a month to $5=1$ or more times/hour $)$ and the severity $(1=$ not serious to $5=$ extremely serious $)$ of the behavior. The ratings are translated via standardized algorithms into an overall maladaptive behaviors score. Higher scores indicate more severe maladaptive behaviors. Reliability and validity of this measure have been established by Bruininks et al. (1996).

Autism symptoms-We measured the number of current autism symptoms at each of the six time points using the ADI-R (Lord, et al., 1994). Thirty-three items from the diagnostic algorithm appropriate for adolescents and adults were administered in interviews with parents. Ratings of current functioning were made at each time of measurement by interviewers who had participated in an approved ADI-R training program. Inter-rater agreement between the interviewers and two supervising psychologists experienced in the diagnosis of autism and in the use of the ADI-R averaged $89 \%$ at Time 1, and the average Kappa was .81. Past research has demonstrated the test-retest reliability, diagnostic validity, convergent validity, and specificity and sensitivity of the items used in the ADI-R diagnostic algorithm (Hill et al., 2001; Lord et al., 1997). Each ADI-R item was scored on the following scale: 0 = no abnormality, 1 = possible abnormality, 2 = definite autistic-type abnormality, 3 = severe autistic-type abnormality.

We recoded each ADI-R item to reflect either no impairment (coded 0 , corresponding to an ADI-R code of 0 ) or some degree of impairment (coded 1, corresponding to an ADI-R code of 1,2 , or 3). This coding strategy has been used previously (Fecteau, Mottron, Berthiaume, \& Burack, 2003; Lounds, Seltzer, Greenberg, \& Shattuck, 2007; Seltzer et al., 2003;

Shattuck et al., 2007; Taylor \& Seltzer, 2010) and is a conservative approach that allows us to capture the number of clinically-significant autism symptoms (instead of the degree of ASD-related abnormality, which is how ADI-R scores are used in the clinical setting). 
In the present analyses we used an overall number of autism symptoms, consisting of items related to restricted repetitive behaviors and interests, reciprocal social interaction impairments, and non-verbal communication impairments (verbal communication impairment items were not included in our overall score as some of the participants were non-verbal). The overall score was created by summing the number of items on which an individual was symptomatic, with higher scores indicating more autism symptoms.

Residential status-At each time point, parents indicated where their adult son or daughter lived $(0=$ co-residing with responding parent; $1=$ living away from the family home).

\section{Between-Persons Independent Variables: Personal Characteristics}

Intellectual disability-Comorbid intellectual disability status $(0=$ no intellectual disability, 1 = intellectual disability) was determined using a variety of sources. Standardized IQ was obtained by administering the Wide Range Intelligence Test (WRIT; Glutting, Adams, \& Sheslow, 2000). The WRIT is a brief measure with strong psychometric properties and both verbal and nonverbal sections. Adaptive behavior was assessed by administering the Vineland Screener (Sparrow, Carter, \& Cicchetti, 1993) to parents. The 45-item screener measured daily living skills in the individual with ASD and correlates well with the full-scale Vineland score ( $r=.87$ to .98$)$. It has high interrater reliability $(r=.98)$ and good external validity (Sparrow, et al., 1993). Using well-established diagnostic guidelines (Luckasson et al., 2002), individuals with standard scores of 70 or below on both IQ and adaptive behavior measures were classified as having ID. For cases where the individual with ASD scored above 70 on either measure, or for whom either of the measures was missing, a review of medical and psychological records by three psychologists, combined with a clinical consensus procedure, was used to determine ID. Although dichotomizing individuals with ASD into ID/no ID groups based on IQ and adaptive behavior reduces variability, it is standard practice among clinicians and researchers, with clinically-meaningful distinctions for families.

\section{Maladaptive behaviors and autism symptoms-See above.}

Independence in Activities of Daily Living-Activities of daily living were measured at Time 1 using the Waisman Activities of Daily Living Scale (W-ADL; Maenner et al., 2013). Parents rated their son or daughter's level of independence on 17 items measuring personal care, housekeeping, and meal-related activities. Each item was rated on a 3-point scale of independence $(0=$ does not perform the task at all; $1=$ performs the task with help; $2=$ performs the task independently) and items were summed. Higher scores indicate greater independence. High levels of reliability and validity have been established (Maenner et al., 2013).

\section{Between-Persons Independent Variables: Contextual Resources}

Family income-At Time 1, parents were also asked about their family's income in the previous year, coded from $1=$ less than $\$ 5,000$ to $13=$ over $\$ 70,000$.

Services: Number received and unmet service needs-At Time 1, parents reported on the availability of twelve services: physical therapy, occupational therapy, speech and language therapy, psychological or psychiatric services, crisis/intervention services, personal care assistance, agency sponsored recreational or social activities, transportation services, income support, medical assistance, respite services, and other family supports. Parents rated whether each service was received, and if not, whether that service was needed. The sum of services received was calculated as our measure of number of services. The sum of services 
needed but not received by the son or daughter was calculated as our measure of unmet service needs (possible range from 0 to 12 for each).

Parental support network-The size of parents' social support network at Time 1 was measured by a modified version of the "convoy model" (Antonucci \& Akiyama, 1987). Responding parents were asked to list up to 10 persons in their network who were important to them. A count of the number of people who were listed was used to indicate the size of the support network, which ranged from 1 to 10 in this sample $(M=7.13, S D=2.49)$.

\section{Data Analysis}

Multilevel modeling, using the Hierarchical Linear Modeling program (HLM; Raudenbush \& Bryk, 2002), was the primary method of data analysis used to examine change in Vocational Index scores over time. Multilevel modeling has several advantages over more traditional ways to study change; one advantage that is especially salient for longitudinal research is its ability to flexibly handle missing data. As long as one occasion of measurement is available, the case can be used in the estimation of effects. However, individuals who have more data points yield more reliable estimates, which are weighted more heavily in the group mean estimates than individuals who have fewer time points (Bryk \& Raudenbush, 1987; Francis, Fletcher, Stuebing, Davidson, \& Thompson, 1991). The use of all available time points for participants reduces bias (Raudenbush \& Bryk, 2002; Singer \& Willett, 2003).

In order to address the first research aim, examining the average 10-year change in Vocational Index scores, an unconditional growth model was estimated that included only the amount of time that had passed since the start of the study. The initial time point of the study was chosen as the intercept, and the time variable was calculated by taking the average amount of years between each of the data collection points (Time $1=0$; Time $2=1.70$; Time $3=3.32$; Time $4=4.87$; Time $5=8.67$; Time $6=10.34$ ). The model resulted in an estimate of the average Vocational Index score at Time 1, and an estimate of the slope reflecting rate of change in Vocational Index scores between Time 1 and Time 6 (Raudenbush \& Bryk, 2002).

After determining the slope, the model was re-estimated, controlling for within-person, time-varying covariates. With six data points, the multilevel model was able to support three time-varying covariates in addition to the study time variable (Singer \& Willett, 2003). After careful consideration, we chose to include the time-varying covariates that are most likely to account for change in Vocational Index scores. Because more severe maladaptive behaviors and autism symptoms have been shown to relate to less independent vocational activities for adults with ASD (Taylor \& Seltzer, 2011b) as well as a host of other outcomes (Baker, Smith, Greenberg, Seltzer, \& Taylor, 2011; Hollway \& Aman, 2011; Lounds, et al., 2007), and because maladaptive behaviors and autism symptoms tend to improve over adulthood (Shattuck, et al., 2007; Taylor \& Seltzer, 2010), we hypothesized that change in Vocational Index scores over time might be accounted for at least in part by changes in behaviors and/or symptoms, and thus these were treated as time-varying covariates. We included residential status as an additional time-varying covariate because change in residential status can affect opportunities for work (e.g., common agencies often provide both residential and vocational services), and because adults with ASD were increasingly likely to be living out of the parental home over time (analyses available from first author). By controlling for change in residential status over the study period, we were able to determine whether changes in Vocational Index scores could be explained by moving out of the parental home. It should be noted that we were unable to consider independence in activities of daily living as a timevarying covariate, even though it is related to vocational activities and tends to change over 
adulthood (Smith, Maenner, \& Seltzer, 2012; Taylor \& Seltzer, 2011b), as it was not measured at all six time points of the study.

The model that included these three time-varying covariates was a better fit to the data than the model without them, $X^{2}(12)=273.23, p<.001$, and thus they were retained in the model for Aims 2 and 3. We chose to treat maladaptive behaviors, autism symptoms, and residential status as random (vs. fixed) effects, as the model allowing these variables to vary randomly was a better fit to the data than the model treating them as fixed effects, $X^{2}(12)=$ $35.02, p<.01$ (Singer \& Willett, 2003).

The second and third research aims addressed whether Time 1 Vocational Index scores (Aim 2), and changes in Vocational Index scores over time (Aim 3) depended on personal characteristics and contextual resources measured at Time 1 . To test these aims, a growth model was again run, with the following between-persons (Level-2) independent variables included as predictors of intercept and slope: ID/no ID; maladaptive behaviors; autism symptoms; independence in activities of daily living; sex; family income; number of services received; unmet service needs; and size of parental support network. Maladaptive behaviors, autism symptoms, and residential status at each time point were included in the models, as well as Time 1 age and residential placement. All between-persons predictors were grand mean centered, and time-varying variables (maladaptive behaviors, autism symptoms, residential status) were centered at each individual's Time 1 score (Singer \& Willett, 2003).

\section{Results}

\section{Aim 1: Examining Average Change in Vocational Index Scores}

Results from the unconditional growth models examining change in Vocational Index scores, both before and after the addition of the within-person, time-varying variables, are presented in Table 1. The intercept estimate of 4.64 suggests that the average vocational placement at the start of the study was between a sheltered setting without community employment (a score of 4 on the Vocational Index) and a sheltered setting with community employment (a score of 5 on the Vocational Index). On average, Vocational Index scores were significantly declining (i.e., adults had vocational placements that were less independent or they had fewer hours of employment) over the study period, which was counter to our hypothesis.

The addition of the three within-persons, time-varying predictors - maladaptive behaviors, autism symptoms, and residential status - is also shown in Table 1. The inclusion of these three predictors did not alter the pattern of results, i.e., average Vocational Index scores continued to significantly decline over time even after accounting for concurrent changes in maladaptive behaviors, autism symptoms, or moving out of the parental home.

\section{Aim 2: Personal Characteristics and Contextual Resources that Predicted Intercept of Vocational Index Scores}

In the next multilevel model (presented in Table 2), the effects of Time 1 between-persons covariates on the intercept and slope of Vocational Index scores were tested.

Somewhat consistent with our hypothesis, two of the personal characteristics of the adults with ASD - a diagnosis of ID and independence in activities of daily living - predicted concurrent Vocational Index scores. Adults with ASD and ID on average had Vocational Index scores that were 1.51 points lower at the start of the study than adults with ASD without ID. The magnitude of this effect can be interpreted in comparison with the residual variability of the intercept. Specifically, not having ID (relative to having ID) corresponded 
to a .91 standard deviation increase in intercept of Vocational Index scores. Vocational Index scores were higher for those who had higher levels of independence in daily living. A 1 standard deviation increase in activities of daily living corresponded to a .26 standard deviation increase in the intercept of Vocational Index scores. Counter to our hypothesis, contextual resources (family income, services received and needed, parental support network) did not independently predict intercept of Vocational Index scores.

\section{Aim 3: Personal Characteristics and Contextual Resources that Predicted Slope of Vocational Index Scores}

The model presented in Table 2 also allowed us to test whether changes over time in Vocational Index scores depended on the personal characteristics and contextual resources of the adults with ASD. The only variable that significantly predicted change in Vocational Index scores over time was sex (see Table 2). Figure 1 depicts the estimates of change in Vocational Index scores for men versus women, resulting from the multi-level models presented in Table 2. Men with ASD had Vocational Index scores that declined at 006 points per year, a rate of change that was not significantly different from zero, B for male slope $=-.006, \mathrm{SE}=.02, \mathrm{p}=.720$. The decline for women was over 15 times greater, at a yearly rate of .110 points, which was significantly different than zero, $\mathrm{B}=-.110, \mathrm{SE}=.04, \mathrm{p}$ $=.004$. The difference in slopes between males and females represents a .71 standard deviation difference with respect to the residual variability of slopes. Over the course of the study, women's Vocational Index scores decreased by an average of over one full point on our nine-point scale.

There was a trend for the number of services received to predict change in Vocational Index scores, with more services predicting greater improvement. A 1 standard deviation increase in the number of services corresponded to a .20 standard deviation increase in the slope (with respect to the residual variability of the slopes). Counter to our hypotheses, the other contextual variables did not predict change in Vocational Index scores.

\section{Discussion}

\section{Aim 1: Average Change in Vocational Index Scores}

To the best of our knowledge, this is the first prospective study to examine the longitudinal course of vocational and educational activities for adults with ASD. Our results are cause for concern. Improvement in vocational activities for adults with ASD was relatively rare. Less than one-fourth of adults were improving to any degree, and less than 5\% had improvements deemed to be substantial (at least one category on the Vocational Index over the study period; see supplemental materials). Nearly three times that number (13.3\%) had scores that substantially declined. These findings stand in stark contrast to the well-established pattern of employment mobility for typically-developing adults at this stage of the lifespan, who tend to improve their occupational positions as they grow older (Light, 2005; Mare, Winship, \& Kubitschek, 1984; Sewell \& Hauser, 1975). The overwhelming lack of improvement in vocational and educational activities over adulthood suggests that patterns of difficulties immediately after high school exit for those with ASD (Shattuck, et al., 2012; Taylor \& Seltzer, 2010, 2011a, 2011b) are not unique to the "transition years." In other words, poor outcomes at high school exit are not a momentary perturbation in development, but are maintained or perhaps exacerbated throughout adulthood.

\section{Aim 2: Predictors of Intercept of Vocational Index Scores}

Whether or not the adult with ASD had a diagnosis of ID was an important predictor of vocational/educational activities. Although we expected a smaller differential between those 
with and without ID over time, which should be reflected by differences in slope, we did not find significant effects of ID on the slope of Vocational Index scores.

Consistent with our hypotheses, greater independence in activities of daily living was associated with more independent vocational and educational activities. Although our earlier work found that activities of daily living, autism symptoms, and maladaptive behaviors were all separately related to vocational independence (Taylor \& Seltzer, 2011b), when incorporating the behavioral indices into one model, activities of daily living emerged as an independent correlate of vocational independence. This is particularly important because the most common predictors of positive outcomes for adults with ASD - better early language and not having a comorbid ID diagnosis (Eaves \& Ho, 2008; Farley, et al., 2009; Howlin, et al., 2004) - are not malleable in adulthood. However, independence in activities of daily living can be changed, and it was associated with vocational activities net of ID in our analyses.

Because the conceptual model motivating this study was focused on vocational/educational activities as the dependent variable, we cannot speak to the directionality of the relation between activities of daily living and vocational independence. It might be that having fewer daily living skills sets an adult with ASD on a path of limited vocational options that is compounded over time. Alternatively, it may be that adults who are in unstimulating work environments lose daily living skills and have behaviors that worsen over time. Additional research using other conceptual and analytic models (e.g., cross-lag models) is needed to tease apart the direction of effects between the key variables in the present analysis.

\section{Aim 3: Predictors of Change in Vocational Index Scores}

Relative to men, declines were particularly pronounced for women with ASD. The average woman's decline in Vocational Index scores was over 15 times greater than that of the average man's decline, resulting in sex differences that became greater over the course of the study. Although this is the first study to examine sex differences in vocational activities for adults with ASD, the observed pattern is somewhat consistent with our hypotheses. These differences also mimic patterns found in the general population, in which women's occupational positions improve less over adulthood relative to that of men (Hauser, Sheridan, \& Warren, 1998; Light, 2005). However, the present findings diverge from those in typically developing adults in an important way. It is not that women with ASD were improving less than men; instead, women's vocational and educational outcomes are actually getting worse over time. Further, the magnitude of this decline is especially concerning, as the average woman declined an entire point on the Vocational Index's nine-point scale.

The one-point difference between categories in our Vocational Index belies the large effect that losing ground in vocational activities has on adults with ASD and their families. For example, moving from a supported job in the community for greater than 10 hours a week (most often about 20-25 hours) to working at a job for fewer than 10 hours a week (which results in a one-point decline on our scale) often means that families become responsible for finding and coordinating activities to replace the lost hours at work or having their adult child be idle for even more hours a week. Further, losing a supported job in the community and entering a segregated, sheltered work arrangement can be a significant blow for adults with ASD and their families and the extent to which they have meaningful engagement with the broader society. Thus, our finding of an average one-point decline for women with ASD is clinically significant in addition to being statistically significant.

There are a number of possible reasons why women with ASD might experience greater declines in vocational and educational activities throughout adulthood. First, it may be that the women were more impaired than the men, thereby placing them on a different vocational 
trajectory. However, follow-up analyses (found in the supplemental materials) suggested that this was not the case, with overwhelming similarities between women and men. Second, it may be that gender stereotypes lead to lowered societal or familial achievement expectations for women with ASD relative to men. One study found that adolescent girls receiving special education services, relative to their male peers, were about twice as likely to report that people expected less of them because of their gender or their disability, their parents were more likely to discourage them from activities due to safety concerns, and they were less likely to have worked for pay while in high school (Powers, et al., 2008).

Differences such as these could lead to limited vocational opportunities for women with ASD relative to men in adulthood.

Third, there might be other differences between women and men with ASD that were not included in our analyses. One promising explanation might be greater risk for comorbid psychiatric disorders in women with ASD. Specifically, anxiety and affective disorders are the most common comorbid psychiatric disorders in adults with ASD (Eaves \& Ho, 2008; Hofvander et al., 2009; Howlin, 2000), and are more common in females than males in the general population (Kessler et al., 1994). It may be that women with ASD are at exceptionally high-risk for anxiety and depression, given the gender pattern in the general population and the higher base-rate in ASD samples. There is some research to support the hypothesis of greater psychopathology in females with ASD relative to males (Hofvander, et al., 2009; Solomon, Miller, Taylor, Hinshaw, \& Carter, 2012) ; however other studies have failed to find gender differences (Lugnegard, Hallerback, \& Gillberg, 2011; Tsakanikos, Underwood, Kravariti, Bouras, \& McCarthy, 2011). Discrepancies between studies likely demonstrate the complexities of exploring this hypothesis further, as psychiatric symptoms can be difficult to distinguish from aspects of ASD, and might be particularly likely to go unidentified among adults with ASD and comorbid ID. Our next step in this line of research is to more thoroughly examine gender differences among adults with ASD, with a focus on uncovering mechanisms that might be responsible for greater decline in vocational and educational activities for women relative to men. Research should also examine whether being female becomes more of a risk factor the further one progresses through adulthood our analyses suggest that this could be the case.

Contrary to our hypothesis, indicators of contextual resources (family income, services, maternal social support) did not independently predict change in Vocational Index scores over time, although there was a trend for receiving a greater number of services to predict improving outcomes. Given the strong relations between individual characteristics (particularly ID, but also independence in activities of daily living) and vocational/ educational activities, as well as the moderate, but consistent correlations between individual characteristics and receipt of formal services (see supplemental Table 3), only a small amount of additional variance in the outcome variable was left to be accounted for by contextual resources (net of individual characteristics) Yet, even with this restricted variance, there was marginal evidence for greater number of services to be related to improving vocational/educational activities over time. Further, the high degree of formal service system engagement in this sample might help explain the lack of significant relations between family income or social connectedness and vocational/educational activities. Only $2.5 \%$ of this sample reported receiving no formal services (see supplemental Table 1). Perhaps income or maternal support might emerge as stronger predictors of outcome in a sample that is more disengaged from the adult service system (with families potentially shouldering a greater burden of funding services).

\section{General Discussion}

Overall, our findings suggest that personal characteristics of adults with ASD are important factors that predict their vocational and educational activities throughout adulthood. It is 
important to note, however, that there are likely many other factors that could account for the lack of improvement overall in vocational and educational activities for adults with ASD. Although it was not modeled empirically in our study, when examining the case studies for those whose vocational activities improved over time, it appeared that improvements were often related to fierce and prolonged advocacy on the part of parents to procure and maintain better vocational activities for their son or daughter with ASD. As parents age, they might advocate less effectively, which could account for the lack of improvement in vocational activities. Future work should focus on the role of parental advocacy, and identify effective advocacy strategies used by parents of youth and adults with ASD. Further, declines in public funding over the course of the study (particularly in Medicaid; Centers for Medicare \& Medicaid Services, 2011) might have limited the vocational activities of adults with ASD, thereby constraining improvement.

As with any study, there are limitations that are worth noting. This is not a nationallyrepresentative sample. Thus, findings from this study may not generalize to other samples with different clinical characteristics or from states that provide varying amounts of government-funded services. Further, this sample of adolescents and adults ranged from 18 to 52 years of age at the start of the study. Although this wide age range can be considered a strength, many of the adults were diagnosed with an ASD before the DSM-IV widened the autism diagnostic criteria. Further, many of this older cohort may not have benefitted from the early intervention services available to families of young children with ASD today. Thus, it is unclear to what extent findings from this cohort will generalize to subsequent cohorts. Third, although there were almost no differences between families who remained in the study and those who were lost to attrition, it is important to note that there was significant attrition in our sample over the 10-year study period (see supplemental materials). Given this attrition, our decision to use longitudinal models that allowed for the inclusion of all participants was critical. Finally, due to the fact that we did not administer all measures at all time points of the study, we were unable to control for change over time in some variables that could account for change in vocational activities, such as independence in activities in daily living or number of formal services received.

These limitations are offset by a number of strengths. This is the first longitudinal study to examine vocational and educational activities over a 10-year period for adults with ASD, allowing us to prospectively examine their course over adulthood. Although there are limits to its generalizeability, our sample was relatively large and recruited from the community, making our findings more generalizeable than many other studies of individuals with ASD. Finally, this is the first empirical study to provide longitudinal evidence that poor vocational and educational outcomes in the years immediately after high school exit persist throughout adulthood, with women with ASD losing ground over time. Future research should continue to examine the malleable factors that promote positive vocational outcomes for adults with ASD.

\section{Supplementary Material}

Refer to Web version on PubMed Central for supplementary material.

\section{Acknowledgments}

This project was supported by two grants from Autism Speaks (J.L. Taylor, PI; M.R. Mailick, PI), the National Institute on Aging (R01 AG08768, M.R. Mailick, PI), and the National Institute of Mental Health (K01 MH92598, J.L. Taylor, PI). Core support was provided by the Eunice Kennedy Shriver National Institute of Child Health and Human Development (P30 HD15052, E.M. Dykens, PI: P30 HD03352, M.R. Mailick, PI) and the National Center for Research Resources (1 UL1 RR024975). We are grateful for the statistical consultation of Dr. Daniel Bolt. 


\section{References}

Antonucci TC, Akiyama H. Social networks in adult life and a preliminary examination of the Convoy Model. Journal of Gerontology. 1987; 42:519-527. doi: 10.1093/geronj/42.5.519. [PubMed: 3624811]

Baker JK, Smith LE, Greenberg JS, Seltzer MM, Taylor JL. Change in Maternal Criticism and Behavior Problems in Adolescents and Adults With Autism Across a 7-Year Period. Journal of Abnormal Psychology. 2011; 120(2):465-475. doi: 10.1037/a0021900. [PubMed: 21319925]

Bruininks, RH.; Woodcock, RW.; Weatherman, RF.; Hill, BK. Scales of Independent Behavior Revised. Riverside Publishing; 1996.

Bryk AS, Raudenbush SW. Application of Hierarchical Linear-Models to Assessing Change. Psychological Bulletin. 1987; 101(1):147-158. doi: 10.1037/0033-2909.101.1.147.

Carstensen LL. Social and emotional patterns in adulthood - Support for socioemotional selectivity theory. Psychology and Aging. 1992; 7(3):331-338. doi: 10.1037/0882-7974.7.3.331. [PubMed: 1388852]

Centers for Disease Control and Prevention. Prevalence of Autism Spectrum Disorders - Autism and Developmental Disabilities Monitoring Network, United States, 2008. Morbidity and Mortality Weekly Report (MMWR). 2012; 61(SS03):1-19.

Centers for Medicare \& Medicaid Services. Medicare \& Medicaid Statistical Supplement: 2011 Edition. 2011. Retrieved from http://www.cms.gov/Research-Statistics-Data-and-Systems/StatisticsTrends-and-Reports/MedicareMedicaidStatSupp/2011.html website

Eaves LC, Ho HH. Young adult outcome of autism spectrum disorders. Journal of Autism and Developmental Disorders. 2008; 38(4):739-747. doi: 10.1007/s10803-007-0441-x. [PubMed: 17764027]

Esbensen AJ, Bishop SL, Seltzer MM, Greenberg JS, Taylor JL. Comparisons between individuals with autism spectrum disorders and individuals with Down syndrome in adulthood. American Journal on Intellectual and Developmental Disabilities. 2010; 115(4):277-290. doi: 10.1352/1944-7558-115.4.277. [PubMed: 20563296]

Farley MA, McMahon WM, Fombonne E, Jenson WR, Miller J, Gardner M, Coon H. Twenty-year outcome for individuals with autism and average or near-average cognitive abilities. Autism Research. 2009; 2(2):109-118. doi: 10.1002/aur.69. [PubMed: 19455645]

Fecteau S, Mottron L, Berthiaume C, Burack JA. Developmental changes of autistic symptoms. Autism. 2003; 7(3):255-268. doi: 10.1177/1362361303007003003. [PubMed: 14516059]

Francis DJ, Fletcher JM, Stuebing KK, Davidson KC, Thompson NM. Analysis of Change - Modeling Individual Growth. Journal of Consulting and Clinical Psychology. 1991; 59(1):27-37. doi: 10.1037/0022-006X.59.1.27. [PubMed: 2002140]

Glutting, JJ.; Adams, W.; Sheslow, D. Wide Range Intelligence Test. Wide Range; Wilmington, DE: 2000.

Hauser, RM.; Sheridan, J.; Warren, JR. Socioeconomic achievements of siblings in the life course: New findings from the Wisconsin Longitudinal Study CDE Working Paper No. 98-02. Center for Demography and Ecology, University of Wisconsin-Madison; Madison, WI: 1998.

Hill A, Bölte S, Petrova G, Beltcheva D, Tacheva S, Poustka F. Stability and interpersonal agreement of the interview-based diagnosis of autism. Psychopathology. 2001; 34(4):187-191. doi: 10.1159/000049305. [PubMed: 11549928]

Hofvander B, Delorme R, Chaste P, Nyden A, Wentz E, Stahlberg O, Leboyer M. Psychiatric and psychosocial problems in adults with normal-intelligence autism spectrum disorders. BMC Psychiatry. 2009; 9:35. doi: 10.1186/1471-244x-9-35. [PubMed: 19515234]

Hollway JA, Aman MG. Sleep correlates of pervasive developmental disorders: A review of the literature. Research in Developmental Disabilities. 2011; 32(5):1399-1421. doi: 10.1016/j.ridd. 2011.04.001. [PubMed: 21570809]

Howlin P. Outcome in adult life for more able individuals with autism or Asperger syndrome. Autism. 2000; 4(1):63-83. doi: 10.1177/1362361300004001005. 
Howlin P, Alcock J, Burkin C. An 8 year follow-up of a specialist supported employment service for high-ability adults with autism or Asperger syndrome. Autism. 2005; 9(5):533-549. doi: 10.1177/1362361305057871. [PubMed: 16287704]

Howlin P, Goode S, Hutton J, Rutter M. Adult outcome for children with autism. Journal of Child Psychology and Psychiatry. 2004; 45(2):212-229. doi: 10.1111/j.1469-7610.2004.00215.x. [PubMed: 14982237]

Kessler RC, McGonagle KA, Zhao S, Nelson CB, Hughes M, Eshleman S, Kendler KS. Lifetime and 12-month prevalence of DSM-III-R psychiatric disorders in the United States. Results from the National Comorbidity Survey. Archives of General Psychiatry. 1994; 51(1):8-19. doi: 10.1001/ archpsyc.1994.03950010008002. [PubMed: 8279933]

Light A. Job mobility and wage growth: evidence from the NLSY79. Monthly Labor Review. 2005; 128(2):33-39.

Lord C, Pickles A, McLennan J, Rutter M, Bregman J, Folstein S, Minshew N. Diagnosing autism: analyses of data from the Autism Diagnostic Interview. Journal of Autism and Developmental Disorders. 1997; 27(5):501-517. doi: 10.1023/A:1025873925661. [PubMed: 9403369]

Lord C, Rutter M, Le Couteur A. Autism Diagnostic Interview - Revised: A revised version of a diagnostic interview for caregivers of individuals with possible pervasive developmental disorders. Journal of Autism and Developmental Disorders. 1994; 24(5):659-685. doi: 10.1007/ BF02172145. [PubMed: 7814313]

Lounds JJ, Seltzer MM, Greenberg JS, Shattuck PT. Transition and change in adolescents and young adults with autism: Longitudinal effects on maternal well-being. American Journal on Mental Retardation. 2007; 112(6):401-417. doi: 10.1352/0895-8017(2007)112[401:TACIAA]2.0.CO;2. [PubMed: 17963433]

Luckasson, R.; Borthwick-Duffy, S.; Buntinx, WHE.; Coulter, DL.; Craig, EM.; Reeve, A.; Tasse, MJ. Mental retardation: Definition, classification, and systems of supports. 10th ed.. American Association on Mental Retardation; Washington, DC: 2002.

Lugnegard T, Hallerback MU, Gillberg C. Psychiatric comorbidity in young adults with a clinical diagnosis of Asperger syndrome. Research in Developmental Disabilities. 2011; 32(5):1910-1917. doi: 10.1016/j.ridd.2011.03.025. [PubMed: 21515028]

Maenner MJ, Smith LE, Hong J, Makuch R, Greenberg JS, Mailick MR. Evaulation of an activities of daily living scale for adolescents and adults with developmental disabilities. Disability and Health Journal. 2013; 6:8-17. doi: 10.1016/j.dhjo.2012.08.005. [PubMed: 23260606]

Mare RD, Winship C, Kubitschek WN. The transition fro youth to adult: Understanding the age pattern of employment. American Journal of Sociology. 1984; 90(2):326-358.

Powers K, Hogansen J, Geenen S, Powers LE, Gil-Kashiwabara E. Gender matters in transition to adulthood: A survey study of adolescents with disabilities and their families. Psychology in the Schools. 2008; 45(4):349-364. doi: 10.1002/Pits.20297.

Raudenbush, SW.; Bryk, AS. Hierarchical linear models : applications and data analysis methods. 2nd ed.. Sage Publications; Thousand Oaks: 2002.

Sameroff AJ. Developmental systems and psychopathology. Development and Psychopathology. 2000; 12(3):297-312. doi: 10.1017/s0954579400003035. [PubMed: 11014740]

Schulenberg JE, Sameroff AJ, Cicchetti D. The transition to adulthood as a critical juncture in the course of psychopathology and mental health. Development and Psychopathology. 2004; 16(4): 799-806. doi: 10.1017/s0954579404040015. [PubMed: 15704815]

Seltzer, MM.; Greenberg, JS.; Taylor, JL.; Smith, LE.; Orsmond, GI.; Esbensen, AJ.; Hong, J. Adolescents and adults with autism spectrum disorders.. In: Amaral, DG.; Dawson, G.; Geschwind, DH., editors. Autism Spectrum Disorders. Oxford University Press; New York: 2011. p. 241-252.

Seltzer MM, Krauss MW, Shattuck PT, Orsmond G, Swe A, Lord C. The symptoms of autism spectrum disorders in adolescence and adulthood. Journal of Autism and Developmental Disorders. 2003; 33(6):565-581. doi: 10.1023/B:JADD.0000005995.02453.0b. [PubMed: 14714927]

Sewell, WH.; Hauser, RM. Education, occupation, and earnings : achievement in the early career. Academic Press; New York: 1975. 
Shattuck PT, Narendorf SC, Cooper B, Sterzing PR, Wagner M, Taylor JL. Postsecondary Education and Employment Among Youth With an Autism Spectrum Disorder. Pediatrics. 2012; 129(6): 1042-1049. doi: 10.1542/peds.2011-2864. [PubMed: 22585766]

Shattuck PT, Seltzer MM, Greenberg JS, Orsmond GI, Bolt D, Kring S, Lord C. Change in autism symptoms and maladaptive behaviors in adolescents and adults with an autism spectrum disorder. Journal of Autism and Developmental Disorders. 2007; 37(9):1735-1747. doi: 10.1007/ s10803-006-0307-7. [PubMed: 17146700]

Shattuck PT, Wagner M, Narendorf S, Sterzing P, Hensley M. Post-High School Service Use Among Young Adults With an Autism Spectrum Disorder. Archives of Pediatrics \& Adolescent Medicine. 2011; 165(2):141-146. doi: 10.1001/archpediatrics.2010.279. [PubMed: 21300654]

Singer, JD.; Willett, JB. Applied longitudinal data analysis : modeling change and event occurrence. Oxford University Press; Oxford ; New York: 2003.

Smith LE, Maenner MJ, Seltzer MM. Developmental Trajectories in Adolescents and Adults With Autism: The Case of Daily Living Skills. Journal of the American Academy of Child and Adolescent Psychiatry. 2012; 51(6):622-631. doi: 10.1016/j.jaac.2012.03.001. [PubMed: 22632621]

Solomon M, Miller M, Taylor S, Hinshaw S, Carter C. Autism Symptoms and Internalizing Psychopathology in Girls and Boys with Autism Spectrum Disorders. Journal of Autism and Developmental Disorders. 2012; 42(1):48-59. doi: 10.1007/s10803-011-1215-z. [PubMed: 21442362]

Sparrow, SS.; Carter, AS.; Cicchetti, D. Vineland Screener. Yale University, Child Study Center; New Haven, CT: 1993.

Taylor JL, Hodapp RM. Doing Nothing: Adults With Disabilities With No Daily Activities and Their Siblings. American Journal on Intellectual and Developmental Disabilities. 2012; 117(1):67-79. doi: 10.1352/1944-7558-117.1.67. [PubMed: 22264113]

Taylor JL, Seltzer MM. Change in the autism phenotype during the transition to adulthood. Journal of Autism and Developmental Disorders. 2010; 40(12):1431-1446. doi: 10.1007/s10803-010-1005-z. [PubMed: 20361245]

Taylor JL, Seltzer MM. Changes in the mother-child relationship during the transition to adulthood for youth with autism spectrum disorders. Journal of Autism and Developmental Disorders. 2011a; 41(10):1397-1410. doi: 10.1007/s10803-010-1166-9. [PubMed: 21184158]

Taylor JL, Seltzer MM. Employment and post-secondary education activities for young adults with autism spectrum disorders during the transition to adulthood. Journal of Autism and Developmental Disorders. 2011b; 41(5):566-574. doi: 10.1007/s10803-010-1070-3. [PubMed: 20640591]

Taylor JL, Seltzer MM. Developing a vocational index for adults with autism spectrum disorders. Journal of Autism and Developmental Disorders. 2012; 42(12):2669-2679. doi: 10.1007/ s10803-012-1524-x. [PubMed: 22466690]

Tsakanikos E, Underwood L, Kravariti E, Bouras N, McCarthy J. Gender differences in co-morbid psychopathology and clinical management in adults with autism spectrum disorders. Research in Autism Spectrum Disorders. 2011; 5(2):803-808. doi: 10.1016/j.rasd.2010.09.009.

U.S. Census Bureau. Money Income in the United States: 1998. Government Printing Office; Washington, DC: 1999. 


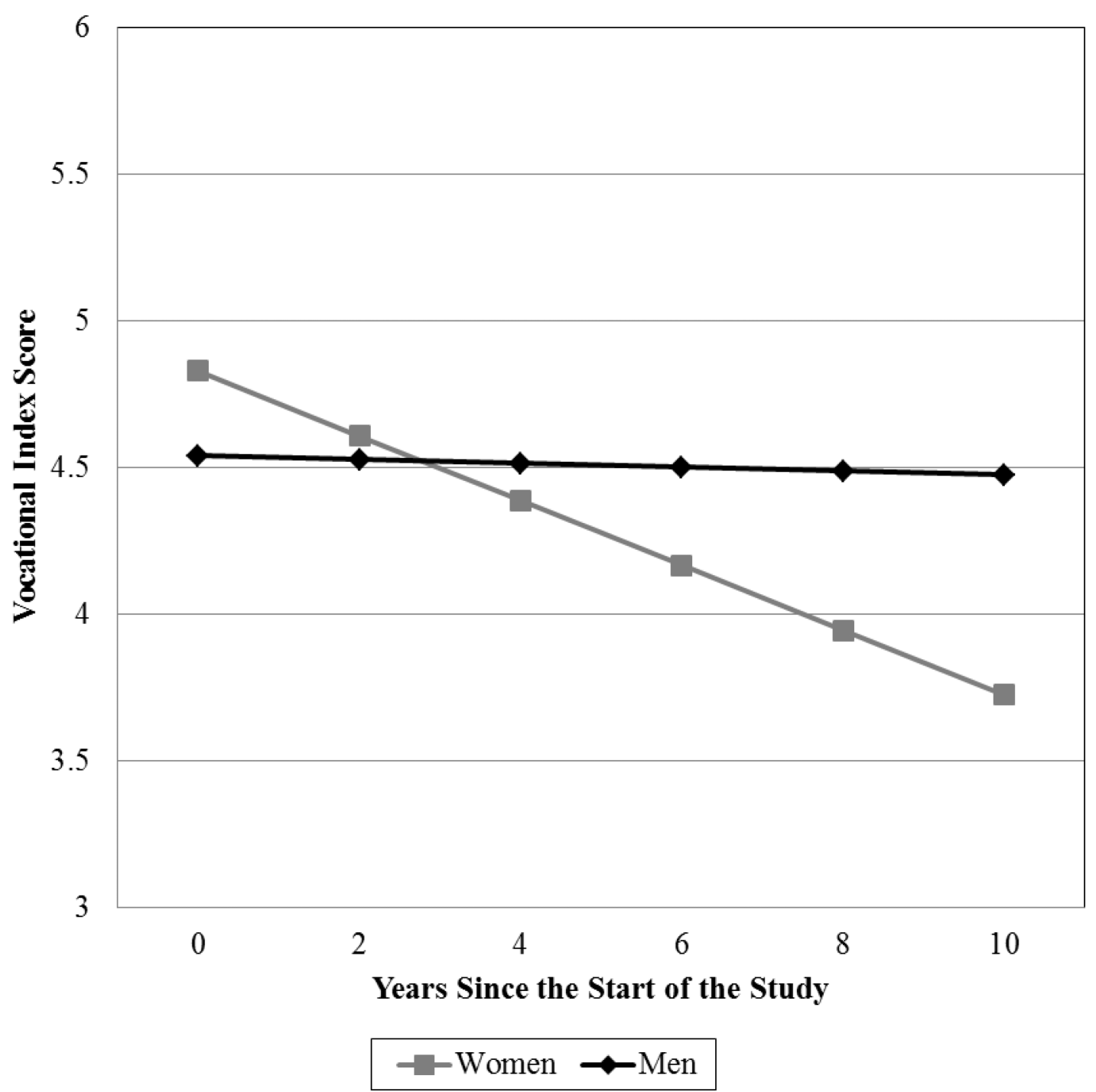

Figure 1.

Model estimates of change in Vocational Index scores over the study period by sex (holding all other variables constant at their means). Women are represented by gray lines and Men are represented by black lines. 


\section{Table 1}

Multilevel Growth Models of Rates of Change in Vocational Index Scores over the Study Period, Before and After the Addition of Within-Persons, Time-Varying Predictors

\begin{tabular}{|c|c|c|c|c|}
\hline \multicolumn{5}{|l|}{ Vocational Index Scores } \\
\hline & \multicolumn{2}{|c|}{ Before Time-Varying Predictors } & \multicolumn{2}{|c|}{ After Time-Varying Predictors } \\
\hline & Coefficient & S.E. & Coefficient & S.E. \\
\hline \multicolumn{5}{|l|}{ Intercept } \\
\hline Time 1 score (Random) & $4.64^{* *}$ & .16 & $4.62^{* *}$ & .16 \\
\hline \multicolumn{5}{|l|}{ Slope } \\
\hline Time (Random) & $-.04^{*}$ & .02 & $-.04^{*}$ & .02 \\
\hline \multicolumn{5}{|l|}{ Time-Varying Predictors } \\
\hline Maladaptive Behaviors (Random) & --- & --- & -.02 & .01 \\
\hline Autism Symptoms (Random) & --- & --- & -.01 & .02 \\
\hline Lives Outside of Parental Home (Random) & --- & --- & -.10 & .40 \\
\hline$p>.05$ & & & & \\
\hline
\end{tabular}


Table 2

Multi-level Model of Between-Persons Effects of Personal and Contextual Variables on Intercept and Slope of Vocational Index Scores

\begin{tabular}{|c|c|c|}
\hline \multirow[b]{2}{*}{ Time 1 Independent Variables } & \multicolumn{2}{|c|}{ Vocational Index Score } \\
\hline & Coefficient & S.E. \\
\hline Intercept (Random) & 4.62 & .14 \\
\hline Intellectual Disability & $-1.51^{* *}$ & .51 \\
\hline Maladaptive Behaviors & -.02 & .02 \\
\hline Autism Symptoms & -.04 & .04 \\
\hline Independence in Activities of Daily Living & $.06^{*}$ & .02 \\
\hline Sex $(1=$ Women $)$ & .29 & .29 \\
\hline Family Income & .03 & .04 \\
\hline Number of Services Received & -.04 & .07 \\
\hline Number of Unmet Service Needs & .02 & .09 \\
\hline Number in Parent's Support Network & -.04 & .06 \\
\hline Age & -.02 & .02 \\
\hline Lives Outside of Parental Home & -.15 & .30 \\
\hline Slope (Random) & $-.04^{*}$ & .02 \\
\hline Intellectual Disability & .04 & .05 \\
\hline Maladaptive Behaviors & -.00 & .00 \\
\hline Autism Symptoms & -.01 & .00 \\
\hline Independence in Activities of Daily Living & .00 & .00 \\
\hline $\operatorname{Sex}(1=$ Women $)$ & $-.10^{* *}$ & .04 \\
\hline Family Income & -.00 & .01 \\
\hline Number of Services Received & $.01^{\dagger}$ & .01 \\
\hline Number of Unmet Service Needs & .01 & .01 \\
\hline Number in Parent's Support Network & -.00 & .01 \\
\hline Age & .00 & .00 \\
\hline Lives Outside of Parental Home & -.01 & .03 \\
\hline \multicolumn{3}{|l|}{ Time-Varying Predictors } \\
\hline Maladaptive Behaviors (Random Slope) & $-.02^{*}$ & .01 \\
\hline Autism Symptoms (Random Slope) & -.01 & .02 \\
\hline Lives Outside Parental Home (Random Slope) & -.20 & .42 \\
\hline \multicolumn{3}{|l|}{ * $p>.05$} \\
\hline$* * *{ }^{*}<.01$ & & \\
\hline
\end{tabular}

